\title{
TRATAMENTO DA MORDIDA CRUZADA ANTERIOR COM APARELHO ORTODÔNTICO REMOVÍVEL: RELATO DE CASO CLÍNICO
}

Kleber Eiji SEINO; Luciano MARCON; Alexandre MORO.

A mordida cruzada anterior (MCA) caracteriza-se pelo fato dos elementos dentários ocuparem posições anormais nos arcos, no sentido lingual ou labial em relação aos antagonistas (ARAUJO, 1982). Pode ser classificada como: dentária, funcional e esquelética (MOYERS, 1991). A dentária resulta da má posição, geralmente linguoversão, envolvendo um ou mais incisivos superiores sem movimento anterior mandibular. $A$ funcional apresenta-se como um padrão de reflexos musculares resultantes da interferência oclusal, levando a mandíbula a uma posição mais anterior; incisivos inferiores se encontram na posição vertical e uma retro-inclinação dos incisivos e lábio superior. A esquelética ocorre devido a uma discrepância na maxila e/ou mandíbula, onde o primeiro molar inferior permanente encontra-se mesial à relação normal com o molar (FERREIRA, 1999). Os autores (McNAMARA, 1987; PROFFIT, 1991, 2002; PETRELLI, 1993; SUGAWARA, 1997; TURLEY, 1998) preconizam a correção da MCA precoce desde que pré-requisitos como cooperação no uso do aparelho e espaço suficiente sejam observados. Neste trabalho é possível verificar através da revisão de literatura e relato de um caso clínico, a eficácia de um aparelho removível com mola digital no tratamento de uma MCA dentária. As molas digitais são amplamente utilizadas na ortodontia (VIGORITO, 1986), e neste estudo observou-se sua efetividade no tratamento. 